\title{
Optimisation of an Advanced Oxidation Protein Products Assay: Its Application to Studies of Oxidative Stress in Diabetes Mellitus
}

\author{
Emma L. Taylor, ${ }^{1}$ Kenneth R. Armstrong, ${ }^{1}$ David Perrett, ${ }^{2}$ \\ Andrew T. Hattersley, ${ }^{1}$ and Paul G. Winyard ${ }^{1}$ \\ ${ }^{1}$ University of Exeter Medical School and NIHR Exeter Clinical Research Facility, University of Exeter, Exeter EX1 2LU, UK \\ ${ }^{2}$ Barts and the London School of Medicine and Dentistry, Queen Mary University of London, London EC1M 6BQ, UK
}

Correspondence should be addressed to Emma L. Taylor; e.l.taylor@exeter.ac.uk and Paul G. Winyard; p.g.winyard@exeter.ac.uk

Received 17 December 2014; Revised 14 April 2015; Accepted 14 April 2015

Academic Editor: Thomas Kietzmann

Copyright @ 2015 Emma L. Taylor et al. This is an open access article distributed under the Creative Commons Attribution License, which permits unrestricted use, distribution, and reproduction in any medium, provided the original work is properly cited.

\begin{abstract}
Advanced oxidation protein products (AOPP) are reportedly elevated in the plasma of patients with a number of diseases, including diabetes mellitus, that involve oxidative stress. However, the accurate measurement of AOPP in human plasma is hampered by the formation of a precipitate following the addition of potassium iodide and glacial acetic acid according to the published assay procedure. Here we describe a modification of the AOPP assay which eliminates interference by precipitation and provides a robust, reliable, and reproducible protocol for the measurement of iodide oxidising capacity in plasma samples (intra-assay CV 1.7-5.3\%, interassay CV 5.3-10.5\%). The improved method revealed a significant association of AOPP levels with age $(p<0.05)$ and hypertension $(p=0.01)$ in EDTA-anticoagulated plasma samples from 52 patients with diabetes and 38 nondiabetic control subjects, suggesting a possible link between plasma oxidising capacity and endothelial and/or vascular dysfunction. There was no significant difference between AOPP concentrations in diabetic (74.8 $\pm 7.2 \mu \mathrm{M}$ chloramine T equivalents) and nondiabetic (75.5 \pm $7.0 \mu \mathrm{M}$ chloramine T equivalents) individuals.
\end{abstract}

\section{Introduction}

The availability of plasma oxidative damage assays which are sensitive and robust is a limiting factor in high-throughput studies of human disease and ageing [1]. The advanced oxidation protein products (AOPP) assay is a widely published method to determine plasma oxidative stress, based on a spectrophotometric assay in a 96-well microplate format [2]. AOPP have been analysed in numerous diseases and are widely regarded as an easily measurable marker of oxidative stress [3-6].

Oxidative stress is a well-established feature of diabetes mellitus and is believed to play an important role in the development of diabetes-related complications [7]. Some studies have found that AOPP are moderately elevated in adult patients with Type 1 diabetes and more markedly elevated in those with Type 2 diabetes [8,9], although others have suggested that AOPP are only significantly increased in
Type 2 diabetes [10]. They have been reported to be elevated in Type 2 diabetes [11], and the concentration correlated with insulin resistance [12] or the presence and/or severity of diabetic complications $[13,14]$, such as retinopathy $[15$, 16] or nephropathy [17]. In juveniles and adolescents with Type 1 diabetes, AOPP were found to accumulate over time and were significantly associated with disease duration [18]. Others suggest that whilst AOPP concentrations are elevated in children with Type 1 diabetes, there is no association with disease duration [19].

We wished to adopt the AOPP assay for our own studies of diabetic patients and control subjects, examining the relationship between oxidative stress and risk factors such as BMI, waist : hip ratio, and blood pressure. However, we report here that the AOPP assay was prone to sample precipitation and consequent poor reproducibility, and we describe a novel modification of the method which measures the total iodide ion $\left(\mathrm{I}^{-}\right)$oxidising capacity of plasma (hereafter referred to as 
TABLE 1: Demographic characteristics of the study cohort.

\begin{tabular}{|c|c|c|c|c|}
\hline & Controls & T2DM & T1/unclassified DM & Total \\
\hline$n$ & 38 & 49 & 3 & 90 \\
\hline Age (years \pm S.D.) & $57.8 \pm 15.8$ & $64.0 \pm 11.0$ & $32.3 \pm 12.7$ & $60.3 \pm 14.6$ \\
\hline Gender (male/female) & $13 / 25$ & $32 / 17$ & $1 / 2$ & $46 / 44$ \\
\hline Smoking status (present/past/never) & $4 / 11 / 23$ & $3 / 27 / 19$ & $0 / 1 / 2$ & $7 / 39 / 44$ \\
\hline Hypertension (absent/present) & $26 / 12$ & $23 / 26$ & $3 / 0$ & $52 / 38$ \\
\hline BMI (mean \pm S.D.) & $27.2 \pm 5.4$ & $29.7 \pm 5.3$ & $25.2 \pm 0.28$ & $28.7 \pm 5.4$ \\
\hline Waist : hip (mean \pm S.D.) & $0.87 \pm 0.10$ & $0.96 \pm 0.09$ & $0.81 \pm 0.11$ & $0.92 \pm 0.10$ \\
\hline
\end{tabular}

$\left.\mathrm{AOPP}_{\text {TIOC }}\right)$. The $\mathrm{AOPP}_{\text {TIOC }}$ assay eliminates interference by sample precipitation and provides greater reproducibility of measurements within samples and a more accurate determination of the ability of a plasma sample to oxidise $\mathrm{I}^{-}$ions.

Application of this modified assay to plasma samples from human diabetic patients and nondiabetic control subjects demonstrated an increase in $\mathrm{AOPP}_{\mathrm{TIOC}}$ with age in both diabetics and nondiabetics and a significant association with the presence of hypertension, although there was no difference in $\mathrm{I}^{-}$oxidising capacity between the two groups.

\section{Materials and Methods}

2.1. Materials. KI, chloramine T hydrate, and PBS were all purchased from Sigma-Aldrich (Gillingham, UK). Glacial acetic acid was from Fisher Scientific (Loughborough, UK) and clear 96-well NUNC Maxisorp microplates were from Greiner Bio One (Stonehouse, UK).

2.2. Plasma Samples. Plasma samples from diabetic patients or nondiabetic controls were collected with informed consent by the NIHR Clinical Research Facility at Peninsula Medical School and analysed for their ability to oxidise $\mathrm{I}^{-}$to $\mathrm{I}_{3}{ }^{-}$. This study had ethical approval from the North and East Devon Research Ethics Committee and was conducted according to the Declaration of Helsinki. A full medical history (including past medical history of myocardial infarction, peripheral vascular disease, hypertension, retinopathy, neuropathy, nephropathy, and cancer) plus physiological data (BMI, waist and hip measurements, and blood pressure) was taken from all participants at the time of venepuncture (Table 1). Routine clinical chemistry measures included triglycerides, HbAlc, and albumin. The mean age of the Type 2 diabetics was $64.0 \pm 11.0$ (mean \pm 1 S.D.) years $(n=49)$, of the Type 1 or unclassified diabetics $32.3 \pm 12.7$ years $(n=3)$, and of the nondiabetic control subjects $57.8 \pm 15.8$ years $(n=38)$. Peripheral blood was collected into EDTA-coated tubes and centrifuged ( $3000 \mathrm{~g}, 10 \mathrm{~min})$. Plasma was removed and dispensed into $100 \mu \mathrm{L}$ aliquots before storage at $-80^{\circ} \mathrm{C}$. Samples were thawed at room temperature before analysis, and repeated freeze-thaw cycles were avoided.

2.3. Previously Published AOPP Assay. For measurement of AOPP, plasma samples were diluted to $10 \%$ in PBS and $200 \mu \mathrm{L}$ applied in triplicate to a 96-well microplate. Standards of chloramine $\mathrm{T}(200 \mu \mathrm{L} ; 0-100 \mu \mathrm{M})$ were added to the plate. $\mathrm{KI}(1.16 \mathrm{M}, 10 \mu \mathrm{L})$ was added to all wells, followed 2 min later by bolus addition of $20 \mu \mathrm{L}$ glacial acetic acid. The optical density was then read immediately at $340 \mathrm{~nm}\left(\mathrm{OD}_{340}\right)$ using a Fluostar Optima plate reader (BMG Labtech Ltd., Aylesbury, UK).

2.4. $A O P P_{\text {TIOC }}$ Assay. Measurement of $\mathrm{AOPP}_{\mathrm{TIOC}}$ by our protocol was carried out as follows. Plasma samples were diluted to $10 \%$ in PBS and $300 \mu \mathrm{L}$ applied in triplicate to a 96-well microplate. Standards of chloramine T $(300 \mu \mathrm{L} ; 0-$ $100 \mu \mathrm{M})$ were added to the plate and a sample blank was prepared by adding $300 \mu \mathrm{L}$ PBS to the microplate. KI $(1.16 \mathrm{M}$, $15 \mu \mathrm{L}$ ) was added to all wells, followed 2 min later by bolus addition of $30 \mu \mathrm{L}$ glacial acetic acid. The microplate was centrifuged ( $5800 \mathrm{~g}, 5 \mathrm{~min}$ ) to pellet precipitated protein, and $230 \mu \mathrm{L}$ of supernatant was transferred to a clean microplate. The $\mathrm{OD}_{340}$ of the supernatant was read $10 \mathrm{~min}$ after the addition of glacial acetic acid. The optical density at $595 \mathrm{~nm}$ $\left(\mathrm{OD}_{595}\right)$, at which wavelength $\mathrm{I}_{3}{ }^{-}$does not absorb [20], was also read as a "nonreaction" measure of sample turbidity and light scattering. The optical density of the sample blank was subtracted from all wells before data analysis.

2.5. Validation Studies. Three different dilutions (5\%, 10\%, and $20 \%$ ) of three plasma samples selected at random were analysed for $\mathrm{AOPP}_{\mathrm{TIOC}}$, followed by multiplication by the dilution factor, to determine whether the same value of $\mathrm{AOPP}_{\text {TIOC }}$ is obtained whatever the sample dilution.

Coefficients of variation were calculated between triplicate optical density measurements of a given sample (interreplicate $\mathrm{CV}$ ), between $\mathrm{AOPP}_{\mathrm{TIOC}}$ values calculated from numerous sets of triplicate measurements of the same sample on the same plate using the same standard curve (intraassay $\mathrm{CV}$ ), and between $\mathrm{AOPP}_{\mathrm{TIOC}}$ values calculated from numerous sets of triplicate measurements of the same sample on different microplates using different standard curves (interassay CV).

2.6. Other Statistical Analyses. Statistical analyses were carried out using GraphPad Prism 5 statistical software package. Unpaired Student's $t$-test was used to evaluate differences in $\mathrm{AOPP}_{\mathrm{TIOC}}$ values involving two sets of categorical data (diabetics versus nondiabetic controls; hypertensive versus nonhypertensive individuals; gender) and ANOVA was used where there were three or more sets of categorical data (smoking status). Linear regression analyses, using Pearson's rank correlation coefficients $(r)$, were performed to assess associations of $\mathrm{AOPP}_{\mathrm{TIOC}}$ values with continuous variables 


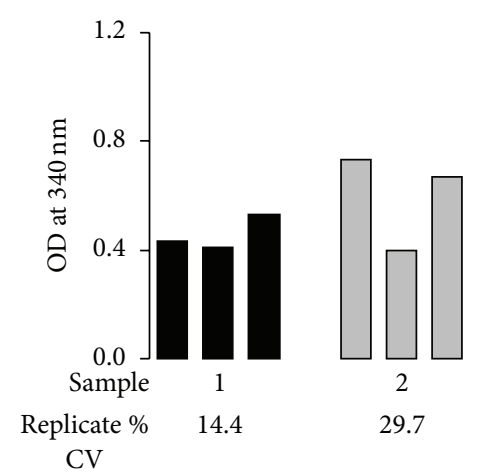

(a)

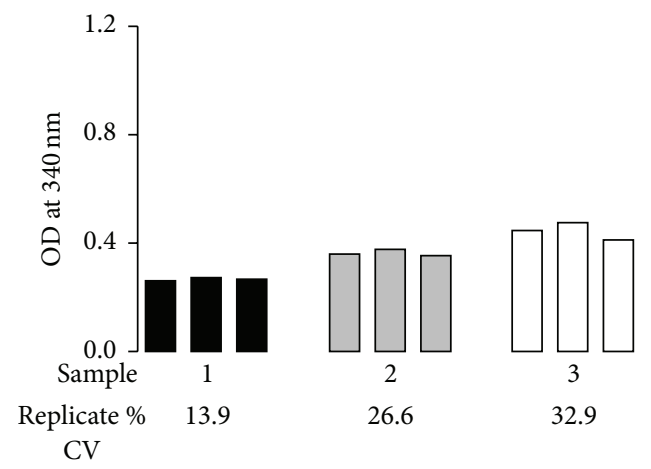

(c)

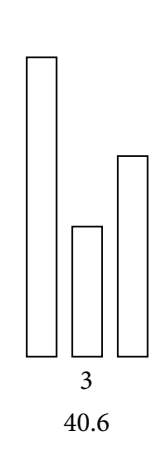

19.9
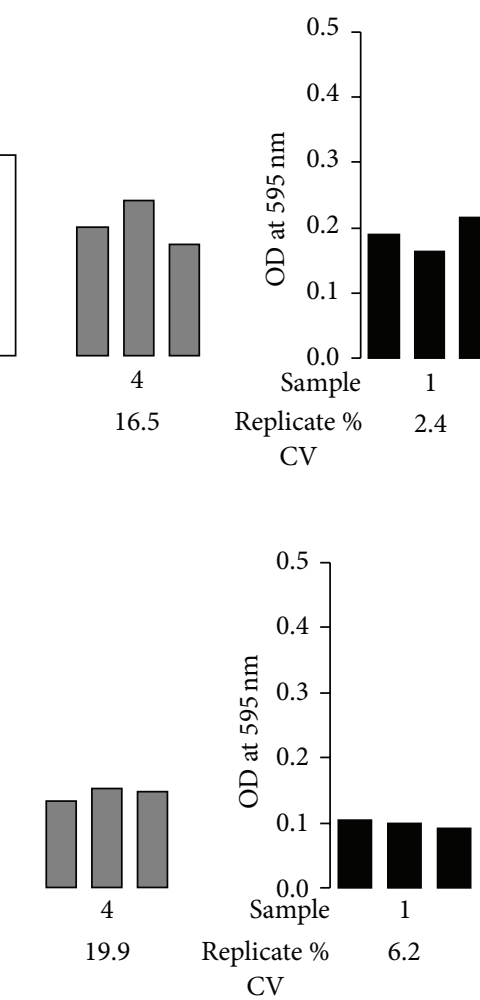

$\mathrm{CV}$

CV
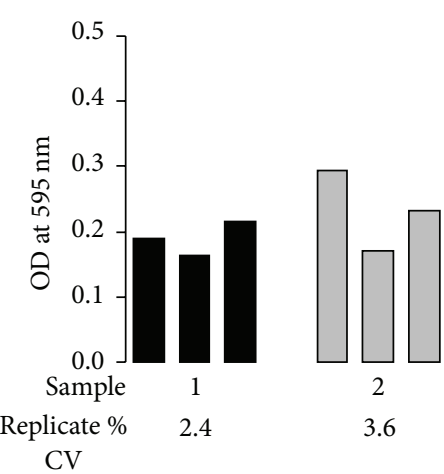

(b)

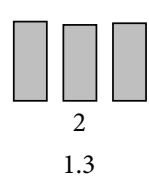

(d)
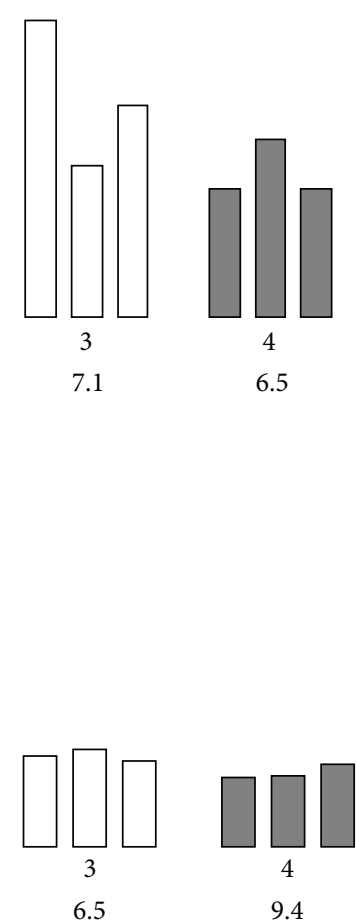

6.5

9.4

Figure 1: Improved reproducibility of the modified $\mathrm{AOPP}_{\mathrm{TIOC}}$ assay after centrifugation $(5800 \mathrm{~g}, 5 \mathrm{~min})$ of the microplate and transfer of supernatant. Four random plasma samples were taken and optical density was measured at a wavelength of $340 \mathrm{~nm}$ following (a) the original protocol and (c) our modified protocol. Optical density was also measured at $595 \mathrm{~nm}$ in (b) the original protocol and (d) our modified protocol in order to examine sample turbidity. Bars represent triplicate optical density values obtained, with each type of shading representing a different plasma sample. Numbers under the appropriate bars represent the \% coefficient of variation (\% CV) of the triplicate measurements for that particular sample.

(age; diabetes disease duration; HbAlc, BMI; waist : hip ratio, serum albumin, and triglyceride concentration). In all cases, a $p$ value $<0.05$ was taken to represent a statistically significant difference.

\section{Results}

Plasma was initially analysed using a previously published AOPP method $[8-10,12,17]$. Of the 77 plasma samples assessed from both diabetic patients and nondiabetic control subjects, only 27 produced an interreplicate CV of less than $20 \%$, and only six of these were under $10 \%$ (see Supplementary Material 1 available online at http://dx.doi.org/10.1155/ 2015/496271). The median interreplicate CV of the 77 samples was $26.2 \%$ (interquartile range 16.7-44.0\%). Consequently, high variability was seen when one sample was analysed on five separate occasions (Supplementary Material 2).

Precipitation was seen in plasma samples from both diabetics (31 of 39 samples; 79.5\%) and control subjects (19 of 38 samples; 50.0\%). The highest \% CVs were seen in the samples that had lower blank optical density values $(r=$ $-0.310, p<0.05$ ), so the variability was not related to high inherent sample optical density; indeed the reverse was true.
The individual microplate wells that gave a high apparent optical density reading corresponded to wells in which a precipitate could be seen. Furthermore, the change in $\mathrm{OD}_{595}$ on addition of $\mathrm{I}^{-}$and acetic acid mirrored the change in $\mathrm{OD}_{340}$ (representative data from four samples is shown in Figure 1, panels (a) and (c)), demonstrating that sample turbidity had altered and variability between replicate values was not alone due to differences in the extent of $\mathrm{I}^{-}$oxidation. Therefore the assay was modified in order to allow the removal of the precipitate from the samples before the optical density was read, to generate a method which we named "AOPP involved increasing all volumes in the assay by $50 \%$, followed by centrifugation of the microplate $(5800 \mathrm{~g}, 5 \mathrm{~min})$ and the subsequent transfer of supernatants $(230 \mu \mathrm{L}$, equal to the final volume per well in the original method) to a fresh microplate before optical density measurements were taken. The increase in sample and reagent volumes by $50 \%$ facilitated the removal of the supernatant after microplate centrifugation, leaving behind the pelleted precipitate, which was discarded.

Four plasma samples were selected to test the reproducibility of replicates using this modified method. The same samples were also analysed by the original method for comparison. Using the original method, interreplicate CVs were all over 10\% (range 14.4-40.6\%; Figure 1(a)) and nonreaction 
TABLE 2: Evaluation of the linearity of $\mathrm{AOPP}_{\mathrm{TIOC}}$ measurements.

\begin{tabular}{|c|c|c|c|c|c|c|c|}
\hline \multirow{2}{*}{ Plasma sample number } & \multirow{2}{*}{ Dilution (\%) } & \multirow{2}{*}{$\begin{array}{c}\text { Mean blank } \\
\mathrm{OD}_{340}\end{array}$} & \multirow{2}{*}{$\begin{array}{c}\text { Mean test } \\
\mathrm{OD}_{340}\end{array}$} & \multicolumn{4}{|c|}{$\mathrm{AOPP}_{\mathrm{TIOC}}(\mu \mathrm{M}$ chloramine $\mathrm{T}$ equivalents $)$} \\
\hline & & & & $\mathrm{AOPP}_{\mathrm{TIOC}} 1^{\mathrm{a}}$ & $\mathrm{x}$ dilution & $\mathrm{AOPP}_{\mathrm{TIOC}} 2^{\mathrm{b}}$ & $\mathrm{x}$ dilution \\
\hline \multirow{3}{*}{1} & 5 & 0.068 & 0.032 & 4.37 & 87.4 & 2.09 & 41.8 \\
\hline & 10 & 0.123 & 0.131 & 17.17 & 171.7 & 4.14 & 41.4 \\
\hline & 20 & 0.209 & 0.602 & 78.38 & 391.9 & 8.85 & 44.3 \\
\hline \multirow{3}{*}{2} & 5 & 0.075 & 0.040 & 5.35 & 107.1 & 2.31 & 46.3 \\
\hline & 10 & 0.130 & 0.161 & 21.07 & 210.7 & 4.59 & 45.9 \\
\hline & 20 & 0.224 & 0.641 & 83.46 & 417.3 & 9.14 & 45.7 \\
\hline \multirow{3}{*}{3} & 5 & 0.123 & 0.058 & 7.76 & 155.2 & 2.79 & 55.7 \\
\hline & 10 & 0.220 & 0.202 & 26.48 & 264.8 & 5.15 & 51.5 \\
\hline & 20 & 0.404 & 0.800 & 104.13 & 520.6 & 10.20 & 51.0 \\
\hline
\end{tabular}

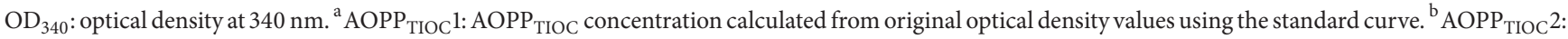
square root of $\mathrm{AOPP}_{\mathrm{TIOC}} 1$.

measurements $\left(\mathrm{OD}_{595}\right)$ were similarly variable (range 13.9$32.9 \%$; Figure $1(\mathrm{c})$ ). In contrast, using our modified protocol, optical density measurements were lower than those seen with the original method and more consistent, with interreplicate CVs all under 10\% (range 2.4-7.1\%; Figure 1(b)). The improved reproducibility of these measurements was mirrored by the low variability in optical density values at $595 \mathrm{~nm}$ (range 1.3-9.4\%; Figure 1(d)), indicating that the precipitate had successfully been removed.

Three plasma samples were selected and diluted to $5 \%$, $10 \%$, and $20 \%$ in PBS. AOPP $\mathrm{TIOC}_{\text {was }}$ wen measured using our method and the values obtained multiplied by the appropriate dilution factor for comparison purposes (Table 2, column 6). Although the optical density of the standards was linear across the range of concentrations tested as previously described [2], and blank OD values of plasma samples (before addition of $\mathrm{I}^{-}$and acetic acid; Table 2, column 3 ) also approximated the expected linear relationship, this was not the case for plasma samples following addition of iodide and acid. As the amount of plasma present in the well doubled $(20 \%$ versus $10 \%$ plasma and $10 \%$ versus $5 \%$ plasma), the associated $\mathrm{AOPP}_{\text {TIOC }}$ increased fourfold. Similarly, a fourfold increase in plasma concentration (20\% versus $5 \%$ plasma) produced an $\mathrm{AOPP}_{\mathrm{TIOC}}$ value that was sixteen times higher. This could be converted to a linear relationship by a square root transformation of $\mathrm{AOPP}_{\mathrm{TIOC}}$ calculated from the standard curve as chloramine $\mathrm{T}$ equivalents. Doing this, and subsequently multiplying by the dilution factor, produced consistent $\mathrm{AOPP}_{\mathrm{TIOC}}$ values. The mean \pm S.D. of the $\mathrm{AOPP}_{\mathrm{TIOC}}$ concentration determined from the three different dilutions was $42.5 \pm 1.6 \mu \mathrm{M}$ in one plasma sample, $46.0 \pm 0.3 \mu \mathrm{M}$ in another, and $53.6 \pm 3.0 \mu \mathrm{M}$ in the third (Table 2, column 8).

This relationship between plasma dilution and $\mathrm{OD}_{340}$ does not merely represent differences in the degree of light scattering due to protein precipitation. Actual fold-change in $\mathrm{OD}$ at a nonspecific wavelength $\left(\mathrm{OD}_{595}\right)$, at which $\mathrm{I}_{3}{ }^{-}$does not absorb light, did not show the same relationship between OD and plasma dilution (data not shown). Thus, association of $\mathrm{OD}$ with the square of the plasma sample concentration was specific for the $340 \mathrm{~nm}$ wavelength at which $\mathrm{I}_{3}{ }^{-}$absorbs light.
It was noted that, despite the centrifugation step, there remained a difference in $\mathrm{OD}_{595}$ between samples (typically ranging from 0.05 to $0.15 \mathrm{OD}$; data not shown) and within the same sample analysed on different days. These differences probably reflect inherent differences in sample composition that are present even before the initiation of protein precipitation and varying degrees of precipitate formation and removal from one sample on different days, respectively. Such differences may interfere with the assay and make comparisons between samples problematic. Therefore, $\mathrm{OD}_{340}$ was additionally normalised to an $\mathrm{OD}_{595}$ of 0.1 , in order to account for these differences, and the resulting normalised $\mathrm{OD}_{340}$ value $\left(\mathrm{nOD}_{340}\right)$ was analysed by linear regression using the standard curve.

Taking the above two points into consideration, we derived the following algorithm for the determination of AOPP TIOC.

Step 1. Calculation of normalised $\mathrm{OD}_{340}\left(\mathrm{nOD}_{340}\right)$ is as follows:

$$
\mathrm{nOD}_{340}=\left[\frac{\left(\mathrm{OD}_{340}\right)}{\left(\mathrm{OD}_{595} \times 10\right)}\right]
$$

Step 2. Calculation of $x$ from $\mathrm{nOD}_{340}$ using linear regression is as follows:

$$
x=\frac{\left(\mathrm{nOD}_{340}-c\right)}{m},
$$

where $y=m x+c$ describes the equation of the standard curve and $y=\mathrm{nOD}_{340}$.

Step 3. Square root transformation of $x\left(x_{\text {srt }}\right)$ is as follows:

$$
x_{\mathrm{srt}}=\left(x^{1 / 2}\right) \text {. }
$$

Step 4. Multiplication by dilution factor is as follows:

$$
\mathrm{AOPP}_{\mathrm{TIOC}}=x_{\text {st }} \times 10
$$

( $\mu \mathrm{M}$ chloramine $\mathrm{T}$ equivalents). 
TABLE 3: Intra-assay and interassay coefficients of variation.

\begin{tabular}{|c|c|c|c|c|c|}
\hline \multicolumn{6}{|c|}{$\mathrm{AOPP}_{\mathrm{TIOC}}$ values ( $\mu \mathrm{M}$ chloramine $\mathrm{T}$ equivalents) } \\
\hline Intra-assay & Sample A $(n=6)$ & Sample B $(n=6)$ & Sample C $(n=6)$ & Sample D $(n=6)$ & Sample E $(n=6)$ \\
\hline Mean & 77.6 & 79.7 & 70.2 & 56.7 & 57.6 \\
\hline S.D. & 1.3 & 2.7 & 3.4 & 2.0 & 3.1 \\
\hline CV (\%) & 1.7 & 3.4 & 4.8 & 3.5 & 5.3 \\
\hline Interassay & Sample F $(n=6)$ & Sample $\mathrm{G}(n=6)$ & Sample H $(n=8)$ & Sample I $(n=7)$ & Sample J $(n=8)$ \\
\hline Mean & 74.6 & 68.9 & 65.3 & 72.5 & 73.2 \\
\hline S.D. & 5.2 & 3.6 & 6.8 & 6.7 & 6.7 \\
\hline CV (\%) & 7.0 & 5.3 & 10.5 & 9.2 & 9.2 \\
\hline
\end{tabular}

The intra-assay and interassay reproducibility of the assay were assessed by measuring $\mathrm{AOPP}_{\mathrm{TIOC}}$ as described above in several plasma samples. $\mathrm{AOPP}_{\mathrm{TIOC}}$ was measured six times in triplicate on the same plate in five plasma samples selected at random (Samples A-E). Table 3 shows that the intra-assay $\mathrm{CV}$ in all five samples was under 6\% (1.7-5.3\%). Interassay CV determinations were carried out using five plasma samples, each of which was measured at least six times over a period of 14 months (Samples F and G) or four months (Samples H-J). Interassay CVs for the five samples ranged from 5.3 to $10.5 \%$, as shown in Table 3.

The modified assay was then applied to 90 plasma samples from individuals with diabetes or control subjects (50 Type 2 diabetics, 3 subjects with unclassified diabetes, and 37 nondiabetic controls). It was found that $\mathrm{AOPP}_{\mathrm{TIOC}}$ values were not significantly different between Type 2 diabetic and nondiabetic individuals ( $p=0.665$ by unpaired Student's $t$ test). Mean ( \pm 1 S.D.) AOPP ${ }_{\text {TIOC }}$ in diabetics was $74.8 \pm 7.2 \mu \mathrm{M}$ chloramine $\mathrm{T}$ equivalents and in controls was $75.5 \pm 7.0 \mu \mathrm{M}$ chloramine $\mathrm{T}$ equivalents. It was found that $\mathrm{AOPP}_{\text {TIOC }}$ values associated significantly with age in both nondiabetic $(r=$ $0.392, p<0.05)$ and Type 2 diabetic $(r=0.489, p<0.05)$ subjects, as assessed by Pearson's rank correlation (Figure 2), although $\mathrm{AOPP}_{\mathrm{TIOC}}$ did not correlate with disease duration in 46 Type 2 diabetes patients for whom this information was available $(r=-0.024 ; p>0.05)$. $\mathrm{AOPP}_{\mathrm{TIOC}}$ also significantly associated with age in the combined dataset of 90 subjects, including the three subjects with Type 1 or unclassified diabetes $(r=0.393, p<0.05)$.

Data from all 90 subjects was analysed in relation to other morbidities that may influence $\mathrm{AOPP}_{\mathrm{TIOC}}$ values, in particular those that increase in prevalence with age. Using this approach, only hypertension ( 38 hypertensive subjects and 52 nonhypertensive subjects) was present in sufficient numbers of subjects to allow valid analyses to be undertaken. It was found that $\mathrm{AOPP}_{\mathrm{TIOC}}$ associates with hypertension $(p=0.01$ by two-tailed unpaired Student's $t$-test), regardless of whether or not the subjects had diabetes (Figure 3). Although the maximum values were similar in nonhypertensive $(88.9 \mu \mathrm{M}$ chloramine $\mathrm{T}$ equivalents) and hypertensive $(87.1 \mu \mathrm{M}$ chloramine $\mathrm{T}$ equivalents) subjects, the data in hypertensive individuals was clustered around the higher end of the range of values such that the minimum value in hypertensives was $67.1 \mu \mathrm{M}$ chloramine $\mathrm{T}$ equivalents compared with $56.6 \mu \mathrm{M}$ chloramine $\mathrm{T}$ equivalents in nonhypertensives. The mean

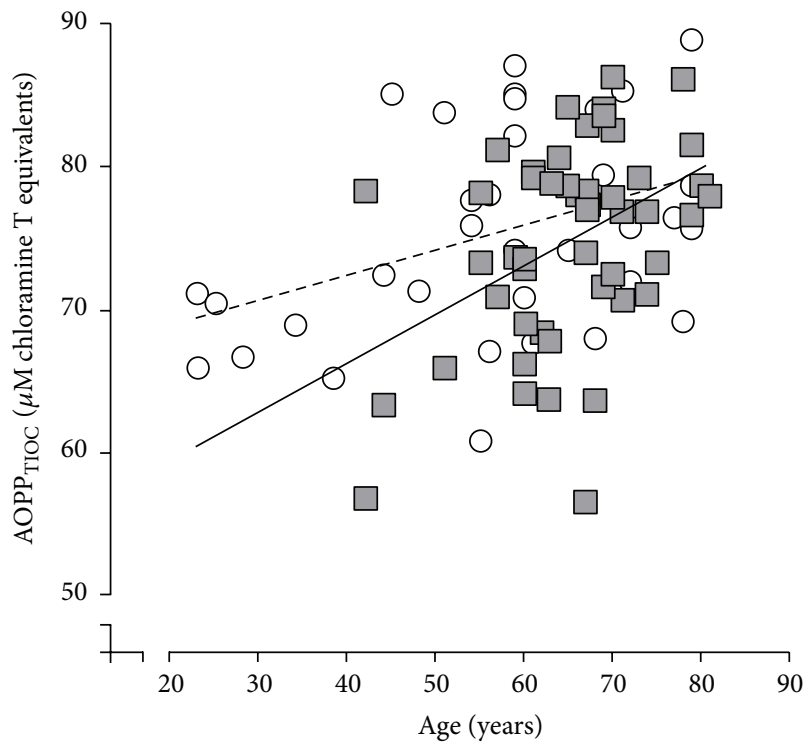

FIgURE 2: Association of $\mathrm{AOPP}_{\mathrm{TIOC}}$ with age in nondiabetic and diabetic subjects. $\mathrm{AOPP}_{\mathrm{TIOC}}$ was measured in 37 subjects without diabetes and 50 patients with Type 2 diabetes and linear regression analyses (Pearson's rank correlation) of $\mathrm{AOPP}_{\mathrm{TIOC}}$ versus age were performed. Both diabetic $(r=0.485)$ and nondiabetic $(r=0.388)$ individuals showed a significant $(p<0.05)$ increase in $\mathrm{AOPP}_{\mathrm{TIOC}}$ with age. Open circles represent data from nondiabetic individuals and dashed line shows the linear trendline through the data. Grey squares represent subjects with Type 2 diabetes and the linear trendline is shown by the solid line.

age of the hypertensive individuals $(66.8 \pm 1.3$ years $)$ was significantly higher $(p<0.001$, two-tailed unpaired Student's $t$-test $)$ than the nonhypertensive individuals $(55.6 \pm 2.3$ years).

No association was seen between $\mathrm{AOPP}_{\mathrm{TIOC}}$ concentration and BMI $(n=90, r=0.085 ; p>0.05)$ as assessed by Pearson's rank correlation analysis. A trend towards an association with waist:hip ratio was seen, but this did not reach statistical significance in this study $(n=87, r=0.195$; $p>0.05)$. Furthermore, there was no correlation between $\operatorname{AOPP}_{\mathrm{TIOC}}$ and $\operatorname{HbAlc}(n=36, r=-0.138 ; p>0.05)$, serum albumin $(n=29 ; r=-0.084 ; p>0.05)$, or triglycerides $(n=27, r=-0.187 ; p>0.05)$. 


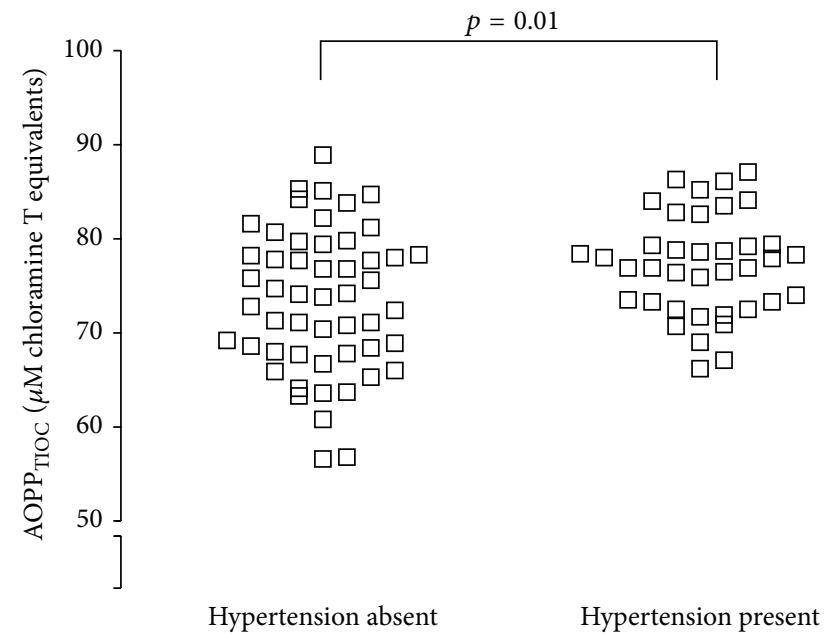

FIgURE 3: Elevated AOPP ${ }_{\text {TIOC }}$ in subjects with hypertension. Subjects were divided into 52 normotensive individuals and 38 subjects diagnosed with hypertension and logistic analysis of their associated plasma AOPP ${ }_{\text {TIOC }}$ concentrations performed by two-tailed Student's $t$-test. A significant $(p<0.05)$ difference in $\mathrm{AOPP}_{\mathrm{TIOC}}$ was found between the two groups.

Smoking status did not influence the values obtained, as mean \pm 1 S.D. $\mathrm{AOPP}_{\mathrm{TIOC}}$ was $75.5 \pm 6.5 \mu \mathrm{M}$ chloramine $\mathrm{T}$ equivalents in nonsmokers $(n=44), 74.6 \pm 7.6 \mu \mathrm{M}$ chloramine T equivalents in past smokers $(n=39)$, and $74.4 \pm$ $7.5 \mu \mathrm{M}$ chloramine T equivalents in present smokers $(n=7)$ ( $p>0.05$ by unpaired one-way ANOVA). Additionally, there was no difference between males $(74.7 \pm 7.3 \mu \mathrm{M}$ chloramine $\mathrm{T}$ equivalents, $n=46)$ and females $(75.5 \pm 6.7 \mu \mathrm{M}$ chloramine $\mathrm{T}$ equivalents, $n=44$ ) as assessed by unpaired Student's $t$-test.

A subset of 23 samples was reanalysed between nine and 22 months after initial analysis in order to determine the reproducibility of incurred samples on repeat analysis. Twenty-two of these samples $(95.7 \%)$ were found to give AOPP concentrations within $20 \%$ of the original values, and $52.2 \%$ of samples were within $10 \%$.

\section{Discussion}

In the present study, we set out to study oxidative stress in patients with diabetes. We used the AOPP assay, in which the capacity of plasma samples to oxidise $\mathrm{I}^{-}$to $\mathrm{I}_{3}{ }^{-}$is analysed [16, $17,21-25]$. Chloramine $\mathrm{T}$ is used as a standard, although a number of plasma constituents contribute to the oxidation of $\mathrm{I}^{-}$to $\mathrm{I}_{3}{ }^{-}$, including hydroperoxides [26], peroxidases [27, 28], and dehydromethionine [29]. The chemical equation of the reaction between chloramines and $\mathrm{I}^{-}$is

$$
\begin{aligned}
\mathrm{RNHCl}+3 \mathrm{I}^{-} \text {(colourless) }+\mathrm{H}^{+} \\
\left.\longleftrightarrow \mathrm{I}_{3}^{-} \text {(yellow-brown }\right)+\mathrm{RNH}_{2}+\mathrm{Cl}^{-}
\end{aligned}
$$

The $\mathrm{I}_{3}{ }^{-}$product has a $\lambda_{\max }$ at $353 \mathrm{~nm}$ [20] and can therefore be measured spectrophotometrically. Recent studies [21, 30] have suggested that oxidised fibrinogen is the oxidiser of $\mathrm{I}^{-}$in this assay, where oxidised fibrinogen may, in turn, result from the activity of myeloperoxidase during inflammation [31]. However, this method showed very large discrepancies between replicate measurements for plasma samples, due to previously unreported interference by a protein precipitate, which varied between wells and between samples. Therefore, in its existing form, the AOPP assay was unsuitable for the reliable determination of AOPP.

We set out to modify the protocol to generate a method that we termed $\mathrm{AOPP}_{\mathrm{TIOC}}$ such that the interreplicate $\mathrm{CV}$ was reduced and the intra- and interassay CVs were minimized [32]. It was necessary to remove the precipitate formed on addition of $\mathrm{I}^{-}$and acetic acid by microplate centrifugation to pellet the precipitate, followed by transfer of supernatant to a new microplate before measurement. The $\mathrm{OD}_{340}$ of triplicate measurements then became acceptably reproducible. There was no correlation between $\mathrm{AOPP}_{\mathrm{TIOC}}$ concentration and serum albumin concentration, demonstrating that the modified method is independent of protein concentration and does not merely reflect increased precipitation in samples with higher protein content.

Reproducibility studies showed the modified assay to be within acceptable limits. Interassay variation was not higher in those samples in which repeat analyses were performed over a longer period of time (14 months) compared to a short period of time (4 months), suggesting that AOPP are stable on storage at $-80^{\circ} \mathrm{C}$ for at least one year. Incurred sample reanalysis (ISR) surpassed the recommended standards for analytical methods. The Crystal City III guidelines issued by the FDA in 2007 recommended that two-thirds of samples must fall within $20 \%$ of the original value on ISR in order for an analytical assay to be deemed valid [33].

We wished to establish if the modified $\mathrm{AOPP}_{\mathrm{TIOC}}$ protocol also demonstrated increased values in diabetic patients. However, no such differences existed between the populations of diabetics and nondiabetics, and there was no association with poor glycaemic control, as measured by glycated haemoglobin (HbAlc).

However, $\mathrm{AOPP}_{\mathrm{TIOC}}$ was significantly associated with the presence of hypertension, a common comorbidity of diabetes. A previous study reported that AOPP concentrations correlate with the degree of arterial stiffness in humans [24], which leads to an elevation of systolic blood pressure and risk of clinical hypertension [34]. Furthermore, it has recently been reported that AOPP is associated with endothelial dysfunction [35] which predisposes to hypertension. Both the above studies involved addition of KI to samples as well as to standards. Thus, our findings support the conclusions of these previous studies which used a method that is closely related to our modified version.

Our inability to reproduce previous studies examining AOPP concentrations in diabetics and nondiabetic controls might be explained by a higher incidence of hypertension in the diabetic cohort of other studies, as hypertension is a common comorbidity of diabetes. Hypertension (or subclinical elevated blood pressure) rather than diabetes per se may have been the factor linked to increased iodide oxidation in the diabetic group. For example, in one study [17], mean blood pressure (systolic \pm 1 S.D./diastolic \pm 1 S.D.) in healthy 
controls was $118 \pm 29 / 72 \pm 19 \mathrm{~mm} \mathrm{Hg}$ and in diabetics was $141 \pm 14 / 76 \pm 10 \mathrm{~mm} \mathrm{Hg}$. Additionally, Kalousová et al. [8] reported that AOPP in patients with Type 2 diabetes (mean blood pressure $139 \pm 9 / 86 \pm 6 \mathrm{~mm} \mathrm{Hg}$ ) was more highly elevated from healthy control values $(p<0.001)$ than in patients with Type 1 diabetes (mean blood pressure $123 \pm$ $13 / 80 \pm 7 \mathrm{~mm} \mathrm{Hg} ; p<0.05$ versus healthy controls). Thus, the patient group with a more strongly elevated mean blood pressure was also the group which showed a higher elevation of mean AOPP concentration.

Alternatively, interference in the AOPP assay by elevated triglycerides [36] due to hyperlipidaemia or differences in fasting status between sample groups may account in part for the previous observations. Triglycerides are carried in the blood in the form of chylomicrons, which scatter light [37], but our modification of the protocol accounts for differences in light scattering by normalising for the optical density of the sample at $595 \mathrm{~nm}$. In one previously published study, the mean triglyceride concentration in healthy controls was $102.7 \pm 48.5 \mathrm{mg} / \mathrm{dL}$ compared to $170.0 \pm 71.3 \mathrm{mg} / \mathrm{dL}$ in diabetics [17]. Another study reported that AOPP was higher in Type 2 diabetes $(2.1 \pm 1.0 \mathrm{mM}$ triglycerides $)$ than Type 1 diabetes $(1.2 \pm 0.5 \mathrm{mM})$ [8]. In a further study, AOPP were reported to be elevated in diabetes $(0.84 \pm 0.07 \mathrm{mM}$ triglycerides), particularly in the presence of complications $(1.17 \pm 0.14 \mathrm{mM})$ compared to controls $(0.63 \pm 0.04 \mathrm{mM})$ [38]. In our study, no association was found between triglyceride concentration and $\mathrm{AOPP}_{\mathrm{TIOC}}$ concentration, suggesting that our modification of the assay is not subject to interference by triglycerides as is the case for other versions of the assay. Similarly, other plasma components, such as NADH and $\mathrm{NADPH}$, absorb light at $340 \mathrm{~nm}$ [39] and may interfere with an assay which only measures the optical density of a plasma sample at this wavelength. However, no association was seen between $\mathrm{AOPP}_{\mathrm{TIOC}}$ concentration and blank $\mathrm{OD}_{340}$ in all subjects assessed during this study. This suggests that our assay is independent of the NADH and NADPH concentration of the sample.

The Free Radical Theory of Ageing postulates that the progressive loss of function observed in the ageing process is due to an accumulation of damage to cellular components by oxidant species [40]. Few studies have thus far examined the validity of this theory in humans, and this is largely due to the lack of robust assays suitable for high-throughput analysis. The oxidising capacity of plasma, as measured by our modified AOPP assay, increased with age in the sample population of 90 subjects, supporting previous findings of an accumulation of oxidative stress in human ageing by other groups [41-47]. It should be noted, however, that the prevalence of hypertension increases with advancing age, and the causeeffect relationship of AOPP in ageing and hypertension has not yet been established. Further studies would be required to determine whether AOPP accumulate with age and predispose to hypertension, or whether AOPP are markers of hypertension that becomes more likely in older individuals.

AOPP have been widely accepted into the field of oxidative stress research, as a marker of plasma protein oxidative damage [8-10, 12, 15, 17, 18, 22, 23, 31, 35, 38, 41, 44, 48-51]. However, on thorough study of the literature, it is apparent that two discrete versions of the AOPP assay exist which both, at first sight, resemble an assay to measure chloramines, in which the oxidation of iodide $\left(\mathrm{I}^{-}\right)$to triiodide $\left(\mathrm{I}_{3}{ }^{-}\right)$by phagocyte-derived chloramines is measured [52]. It is clear that the analytes measured in the two versions of the AOPP assay are different, but this discrepancy has not previously been pointed out.

In one version of the AOPP assay, optical density of the plasma sample at $340 \mathrm{~nm}$ is simply measured in the presence of acid $[4,5,36,48,49]$ and is apparently based on the rationale that oxidatively modified proteins absorb light at $340 \mathrm{~nm}$ to a greater extent than native proteins under acidic conditions [53]. The relevance of using chloramine $\mathrm{T}$ as a standard $[2,36,49,50]$ is not made clear. In this version of the assay, the measured AOPP are reported to be carried largely by oxidised albumin and are made up of numerous chromophores including dityrosine, pentosidine, and protein carbonyls [53], but AOPP themselves have no measured oxidising capacity. The second version of the method examines the iodide oxidising capacity of plasma, and this is the principle of the assay developed in the present study $[8-10,12,17]$. Using this version of the assay, AOPP are reported to comprise oxidised fibrinogen $[21,30]$.

AOPP have previously been reported to be elevated in both Type 1 and Type 2 diabetic patients compared with healthy controls, but some studies were carried out using the AOPP protocol in which $\mathrm{KI}$ is only added to the standards [38] and others examining plasma iodide oxidising capacity $[8-10,12,17]$. In yet further studies on AOPP in diabetes, it was unclear which protocol was followed $[15,18$, 51]. Differences in methodology may partially explain the discrepancy in AOPP values published in previous studies of oxidative stress. Reported AOPP concentrations in control groups vary greatly between studies, with concentrations ranging from $0.11 \pm 0.05$ [17] to $259 \pm 75 \mu \mathrm{M}$ [12] chloramine $\mathrm{T}$ equivalents, and on examination of the two versions of the assay it appears that the two published AOPP methods measure different analytes. Additionally, failure to correct for precipitation or inherent triglyceride concentrations may influence AOPP concentrations determined during these studies. The availability of a robust assay of $\mathrm{AOPP}_{\mathrm{TIOC}}$ will facilitate further studies to characterise the components responsible for plasma TIOC activity.

In summary, we have identified inconsistencies in the published protocols by which AOPP is measured, which have not previously been highlighted. One such method is confounded by precipitation which causes variability between replicates and overestimation of AOPP concentrations. We have developed a modified version of this method (named $\mathrm{AOPP}_{\mathrm{TIOC}}$ ) which eliminates the effect of precipitation and has been shown to increase with age in human plasma and is significantly associated with hypertension, suggesting that it may be a marker of endothelial dysfunction. We strongly urge other researchers wishing to publish AOPP data to be particularly careful in the description of their methodology, especially with regard to whether or not $\mathrm{I}^{-}$is added to plasma samples as well as to standards. 


\author{
Abbreviations \\ AOPP: Advanced oxidation protein products \\ BMI: Body mass index \\ CV: $\quad$ Coefficient of variation \\ KI: $\quad$ Potassium iodide \\ OD: Optical density \\ PBS: Phosphate buffered saline \\ TIOC: Total iodide oxidising capacity.
}

\section{Disclaimer}

The views and opinions shown within this paper are those of the authors and do not necessarily represent those of the NIHR, NHS, or the Department of Health.

\section{Conflict of Interests}

The authors declare that there is no conflict of interests regarding the publication of this paper.

\section{Authors' Contribution}

Emma L. Taylor was involved in experimental design, carried out laboratory experiments, analysed and interpreted data, and wrote the paper. Kenneth R. Armstrong carried out laboratory experiments, analysed data, and reviewed the paper. David Perrett was involved in data interpretation and helped in writing the paper. Andrew T. Hattersley is the Clinical Director of the NIHR Exeter Clinical Research Facility and principal investigator of the EXTRA study of diabetes, which contributed plasma samples for analysis. Andrew T. Hattersley also helped in writing the paper. Paul G. Winyard was the principal investigator on this study and was involved in experimental design and data interpretation and writing the paper.

\section{Funding}

This study was funded by the United Kingdom's BBSRC and EPSRC "Strategic Promotion of Ageing Research Capacity" (SPARC) scheme and supported by the NIHR Exeter Clinical Research Facility.

\section{Acknowledgments}

The authors would like to acknowledge the contribution of the research nurses at the NIHR Exeter Clinical Research Facility (Anna Steele, Jane Rowley, Gayle Githens-Mazer, and Zena Troop) employed as part of the Diabetes Alliance for Research in England (DARE) for collection of blood samples, plus recording of anthropometric data and medical history, and Anita Hill for database management. Thanks also are due to Professor Peter Winlove (University of Exeter) for helpful advice. Importantly, the authors thank all the study volunteers.

\section{References}

[1] D. J. Pattison and P. G. Winyard, "Dietary antioxidants in inflammatory arthritis: Do they have any role in etiology or therapy?" Nature Clinical Practice Rheumatology, vol. 4, no. 11, pp. 590-596, 2008.

[2] V. Witko-Sarsat, M. Friedlander, C. Capeillère-Blandin et al., "Advanced oxidation protein products as a novel marker of oxidative stress in uremia," Kidney International, vol. 49, pp. 1304-1313, 1996.

[3] K. F. Peng, X. F. Wu, H. W. Zhao, and Y. Sun, "Advanced oxidation protein products induce monocyte chemoattractant protein-1 expression via p38 mitogen-activated protein kinase activation in rat vascular smooth muscle cells," Chinese Medical Journal, vol. 119, no. 13, pp. 1088-1093, 2006.

[4] V. Witko-Sarsat, M. Friedlander, T. N. Khoa et al., "Advanced oxidation protein products as novel mediators of inflammation and monocyte activation in chronic renal failure," Journal of Immunology, vol. 161, no. 5, pp. 2524-2532, 1998.

[5] V. Witko-Sarsat, V. Gausson, and B. Descamps-Latscha, "Are advanced oxidation protein products potential uremic toxins?" Kidney International, Supplement, vol. 63, supplement, pp. S11S14, 2003.

[6] Y. Iwao, K. Nakajou, R. Nagai et al., "CD36 is one of important receptors promoting renal tubular injury by advanced oxidation protein products," The American Journal of Physiology-Renal Physiology, vol. 295, no. 6, pp. F1871-F1880, 2008.

[7] F. Giacco and M. Brownlee, "Oxidative stress and diabetic complications," Circulation Research, vol. 107, no. 9, pp. 10581070, 2010.

[8] M. Kalousová, J. Škrha, and T. Zima, "Advanced glycation endproducts and advanced oxidation protein products in patients with diabetes mellitus," Physiological Research, vol. 51, no. 6, pp. 597-604, 2002.

[9] M. A. Abou-Seif and A.-A. Youssef, "Evaluation of some biochemical changes in diabetic patients," Clinica Chimica Acta, vol. 346, no. 2, pp. 161-170, 2004.

[10] M. Kalousová, L. Fialová, J. Skrha et al., "Oxidative stress, inflammation and autoimmune reaction in type 1 and type 2 diabetes mellitus," Prague Medical Report, vol. 105, no. 1, pp. 21$28,2004$.

[11] V. Jakuš, E. Sándorová, J. Kalninová, and B. Krahulec, "Monitoring of glycation, oxidative stress and inflammation in relation to the occurrence of vascular complications in patients with type 2 diabetes mellitus," Physiological Research, vol. 63, no. 3, pp. 297309, 2014.

[12] H. Koçak, Y. Öner-İyidoğan, F. Gürdöl et al., "Advanced oxidation protein products in obese women: its relation to insulin resistance and resistin," Clinical and Experimental Medicine, vol. 7, no. 4, pp. 173-178, 2007.

[13] S. Bansal, D. Chawla, M. Siddarth, B. D. Banerjee, S. V. Madhu, and A. K. Tripathi, "A study on serum advanced glycation end products and its association with oxidative stress and paraoxonase activity in type 2 diabetic patients with vascular complications," Clinical Biochemistry, vol. 46, no. 1-2, pp. 109114, 2013.

[14] O. Tabak, R. Gelisgen, H. Erman et al., "Oxidative lipid, protein, and DNA damage as oxidative stress markers in vascular complications of diabetes mellitus," Clinical \& Investigative Medicine, vol. 34, no. 3, pp. 163-171, 2011. 
[15] H.-Z. Pan, L. Zhang, M.-Y. Guo et al., "The oxidative stress status in diabetes mellitus and diabetic nephropathy," Acta Diabetologica, vol. 47, no. 1, supplement, pp. S71-S76, 2010.

[16] Z. Yildirim, N. I. Ucgun, N. Kilic, E. Gursel, and A. SepiciDincel, "Antioxidant enzymes and diabetic retinopathy," Annals of the New York Academy of Sciences, vol. 1100, no. 1, pp. 199-206, 2007.

[17] A. Piwowar, M. Knapik-Kordecka, J. Szczecínska, and M. Warwas, "Plasma glycooxidation protein products in type 2 diabetic patients with nephropathy," Diabetes/Metabolism Research and Reviews, vol. 24, no. 7, pp. 549-553, 2008.

[18] M. Krzystek-Korpacka, B. Salmonowicz, D. Boehm et al., "Diagnostic potential of oxidative stress markers in children and adolescents with type 1 diabetes," Clinical Biochemistry, vol. 41, no. 1-2, pp. 48-55, 2008.

[19] V. Jakuš, M. Sapák, and J. Kostolanská, "Circulating TGF- $\beta 1$, glycation, and oxidation in children with diabetes mellitus type 1," Experimental Diabetes Research, vol. 2012, Article ID 510902, 7 pages, 2012.

[20] N. M. Alexander, "A spectrophotometric assay for iodide oxidation by thyroid peroxidase," Analytical Biochemistry, vol. 4, no. 4, pp. 341-345, 1962.

[21] L. Selmeci, M. Székely, P. Soós et al., "Human blood plasma advanced oxidation protein products (AOPP) correlates with fibrinogen levels," Free Radical Research, vol. 40, no. 9, pp. 952958, 2006.

[22] R. Kayali, U. Çakatay, H. Uzun, and H. Genç, "Gender difference as regards myocardial protein oxidation in aged rats: male rats have increased oxidative protein damage," Biogerontology, vol. 8, no. 6, pp. 653-661, 2007.

[23] E. Matteucci, E. Biasci, and O. Giampietro, "Advanced oxidation protein products in plasma: stability during storage and correlation with other clinical characteristics," Acta Diabetologica, vol. 38, no. 4, pp. 187-189, 2001.

[24] A. Wykretowicz, K. Adamska, T. Krauze et al., "The plasma concentration of advanced oxidation protein products and arterial stiffness in apparently healthy adults," Free Radical Research, vol. 41, no. 6, pp. 645-649, 2007.

[25] L. Selmeci, L. Seres, M. Antal, J. Lukács, A. Regöly-Mérei, and G. Acsády, "Advanced oxidation protein products (AOPP) for monitoring oxidative stress in critically ill patients: a simple, fast and inexpensive automated technique," Clinical Chemistry and Laboratory Medicine, vol. 43, no. 3, pp. 294-297, 2005.

[26] V. Chajès, W. Sattler, M. Stultschnig, and G. M. Kostner, "Photometric evaluation of lipid peroxidation products in human plasma and copper oxidized low density lipoproteins: correlation of different oxidation parameters," Atherosclerosis, vol. 121, no. 2, pp. 193-203, 1996.

[27] J.-F. Lagorce, J.-C. Thomes, G. Catanzano, J. Buxeraud, M. Raby, and C. Raby, "Formation of molecular iodine during oxidation of iodide by the peroxidase $/ \mathrm{H}_{2} \mathrm{O}_{2}$ system. Implications for antithyroid therapy," Biochemical Pharmacology, vol. 42, supplement 1, no. 1, pp. S89-S92, 1991.

[28] F. Tatzber, S. Griebenow, W. Wonisch, and R. Winkler, "Dual method for the determination of peroxidase activity and total peroxides-iodide leads to a significant increase of peroxidase activity in human sera," Analytical Biochemistry, vol. 316, no. 2, pp. 147-153, 2003.

[29] A. V. Peskin, R. Turner, G. J. Maghzal, C. C. Winterbourn, and A. J. Kettle, "Oxidation of methionine to dehydromethionine by reactive halogen species generated by neutrophils," Biochemistry, vol. 48, no. 42, pp. 10175-10182, 2009.
[30] L. Selmeci, L. Seres, P. Soós, M. Székely, and G. Acsády, "Kinetic assay for the determination of the oxidative stress biomarker, advanced oxidation protein products (AOPP) in the human blood plasma," Acta Physiologica Hungarica, vol. 95, no. 2, pp. 209-218, 2008.

[31] M. Dhiman, J. G. Estrada-Franco, J. M. Pando et al., "Increased myeloperoxidase activity and protein nitration are indicators of inflammation in patients with Chagas' disease," Clinical and Vaccine Immunology, vol. 16, no. 5, pp. 660-666, 2009.

[32] G. F. Reed, F. Lynn, and B. D. Meade, "Use of coefficient of variation in assessing variability of quantitative assays," Clinical and Diagnostic Laboratory Immunology, vol. 9, no. 6, pp. 12351239, 2002.

[33] D. M. Fast, M. Kelley, C. T. Viswanathan et al., "Workshop report and follow-up-AAPS workshop on current topics in GLP bioanalysis: assay reproducibility for incurred samplesimplications of Crystal City recommendations," The AAPS Journal, vol. 11, no. 2, pp. 238-241, 2009.

[34] S. Laurent and P. Boutouyrie, "Arterial stiffness: a new surrogate end point for cardiovascular disease?" Journal of Nephrology, vol. 20, supplement 12, pp. S45-S50, 2007.

[35] H. Kocak, S. Gumuslu, E. Sahin et al., "Advanced oxidative protein products are independently associated with endothelial function in peritoneal dialysis patients," Nephrology, vol. 14, no. 3, pp. 273-280, 2009.

[36] A. Valli, M. E. Suliman, N. Meert et al., "Overestimation of advanced oxidation protein products in uremic plasma due to presence of triglycerides and other endogenous factors," Clinica Chimica Acta, vol. 379, no. 1-2, pp. 87-94, 2007.

[37] S. Tazuma, H. Miura, N. Hirano et al., "A quantitative assessment of serum chylomicron by light scattering intensity: application to the intestinal fat absorption test," Journal of Gastroenterology and Hepatology, vol. 12, no. 11, pp. 713-718, 1997.

[38] P. Martín-Gallán, A. Carrascosa, M. Gussinyé, and C. Domínguez, "Biomarkers of diabetes-associated oxidative stress and antioxidant status in young diabetic patients with or without subclinical complications," Free Radical Biology and Medicine, vol. 34, no. 12, pp. 1563-1574, 2003.

[39] Z. Zhang, J. Yu, and R. C. Stanton, "A method for determination of pyridine nucleotides using a single extract," Analytical Biochemistry, vol. 285, no. 1, pp. 163-167, 2000.

[40] D. Harman, "Aging: a theory based on free radical and radiation chemistry," Journal of Gerontology, vol. 11, no. 3, pp. 298-300, 1956.

[41] L. Arranz, C. Fernández, A. Rodríguez, J. M. Ribera, and M. de la Fuente, "The glutathione precursor N-acetylcysteine improves immune function in postmenopausal women," Free Radical Biology and Medicine, vol. 45, no. 9, pp. 1252-1262, 2008.

[42] R. D. Semba, L. Ferrucci, K. Sun et al., "Oxidative stress is associated with greater mortality in older women living in the community," Journal of the American Geriatrics Society, vol. 55, no. 9, pp. 1421-1425, 2007.

[43] C. Howard, L. Ferrucci, K. Sun et al., "Oxidative protein damage is associated with poor grip strength among older women living in the community," Journal of Applied Physiology, vol. 103, no. 1, pp. 17-20, 2007.

[44] U. Çakatay, R. Kayali, and H. Uzun, "Relation of plasma protein oxidation parameters and paraoxonase activity in the ageing population," Clinical and Experimental Medicine, vol. 8, no. 1, pp. 51-57, 2008. 
[45] V. M. Mendoza-Núñez, M. Ruiz-Ramos, M. A. SánchezRodríguez, R. Retana-Ugalde, and J. L. Muñoz-Sánchez, "Agingrelated oxidative stress in healthy humans," Tohoku Journal of Experimental Medicine, vol. 213, no. 3, pp. 261-268, 2007.

[46] P. C. Mittal and R. Kant, "Correlation of increased oxidative stress to body weight in disease-free post menopausal women," Clinical Biochemistry, vol. 42, no. 10-11, pp. 1007-1011, 2009.

[47] N. Sakano, N. Takahashi, D.-H. Wang et al., "Plasma 3nitrotyrosine, urinary 8-isoprostane and 8-OHdG among healthy Japanese people," Free Radical Research, vol. 43, no. 2, pp. 183-192, 2009.

[48] B. Anderstam, B.-H. Ann-Christin, A. Valli, P. Stenvinkel, B. Lindholm, and M. E. Suliman, "Modification of the oxidative stress biomarker AOPP assay: application in uremic samples," Clinica Chimica Acta, vol. 393, no. 2, pp. 114-118, 2008.

[49] M. Anraku, K. Kitamura, R. Shintomo et al., "Effect of intravenous iron administration frequency on AOPP and inflammatory biomarkers in chronic hemodialysis patients: a pilot study," Clinical Biochemistry, vol. 41, no. 14-15, pp. 1168-1174, 2008.

[50] E. Boulanger, O. Moranne, M.-P. Wautier et al., "Changes in glycation and oxidation markers in patients starting peritoneal dialysis: a pilot study," Peritoneal Dialysis International, vol. 26, no. 2, pp. 207-212, 2006.

[51] L. Gil-del Valle, L. D. L. C. Milian, A. Toledo, N. Vilaró, R. Tápanes, and M. A. Otero, "Altered redox status in patients with diabetes mellitus type I," Pharmacological Research, vol. 51, no. 4, pp. 375-380, 2005.

[52] V. Witko and B. Descamps-Latscha, "Microtiter plate assay for phagocyte-derived taurine-chloramines," Journal of Clinical Laboratory Analysis, vol. 6, no. 1, pp. 47-53, 1992.

[53] C. Capeillère-Blandin, V. Gausson, B. Descamps-Latscha, and V. Witko-Sarsat, "Biochemical and spectrophotometric significance of advanced oxidized protein products," Biochimica et Biophysica Acta-Molecular Basis of Disease, vol. 1689, no. 2, pp. 91-102, 2004. 


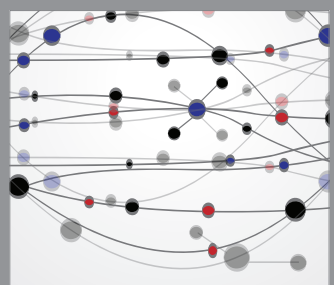

The Scientific World Journal
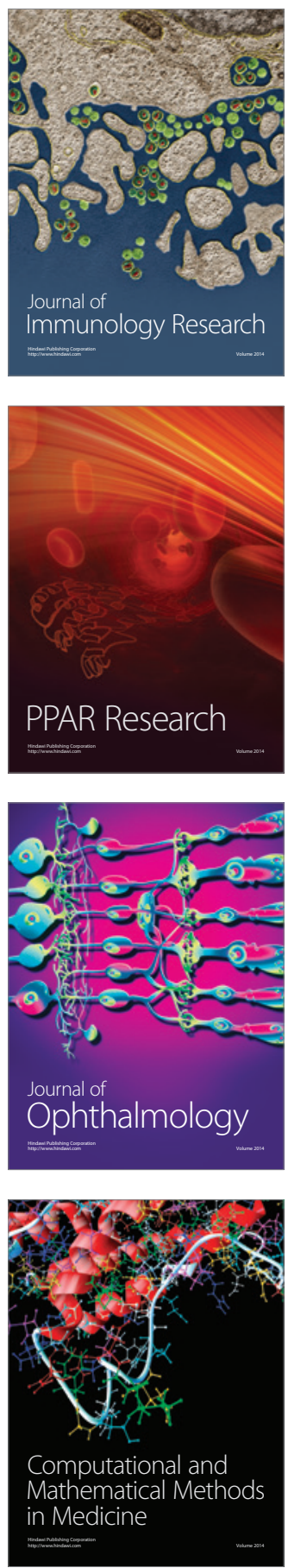

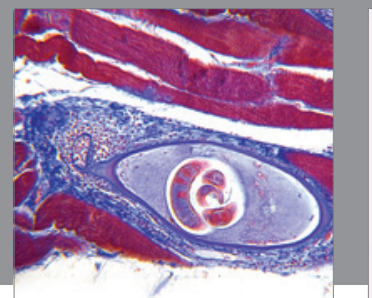

Gastroenterology

Research and Practice
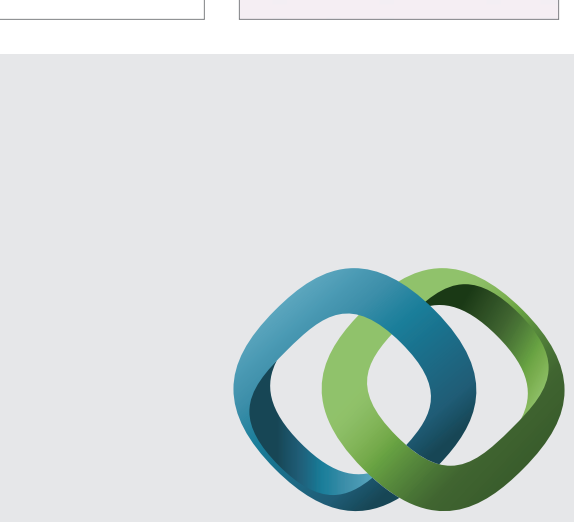

\section{Hindawi}

Submit your manuscripts at

http://www.hindawi.com
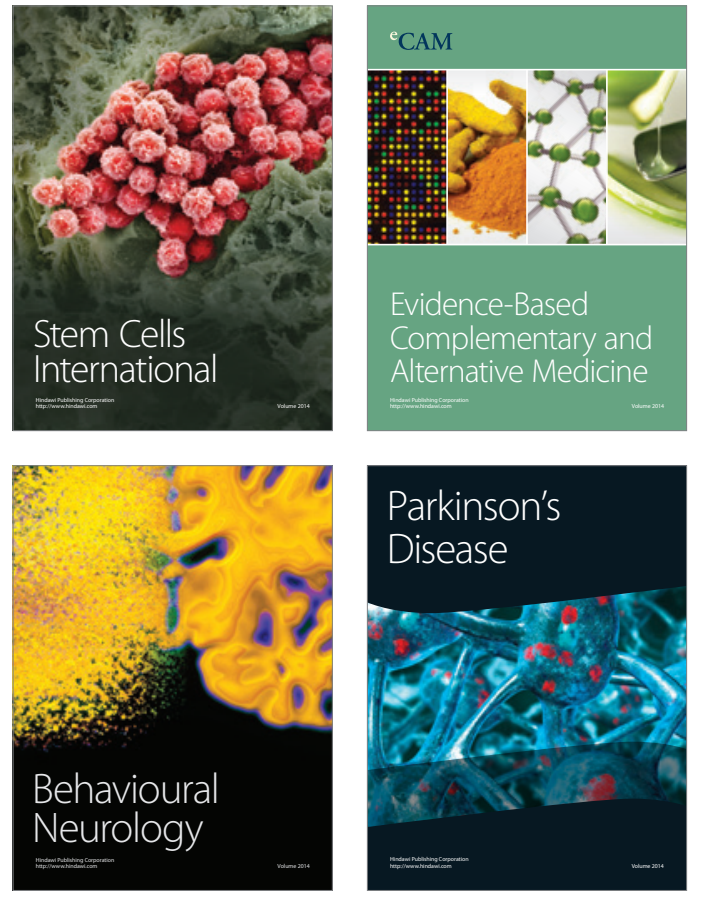
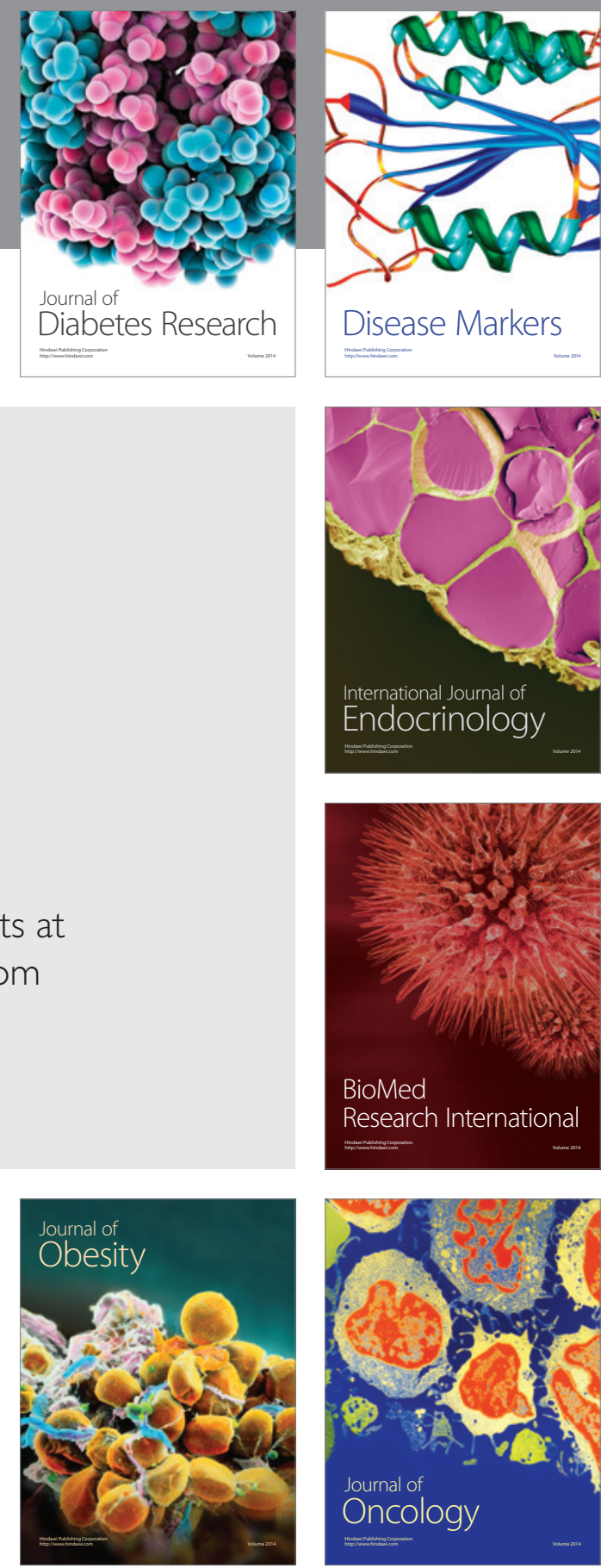

Disease Markers
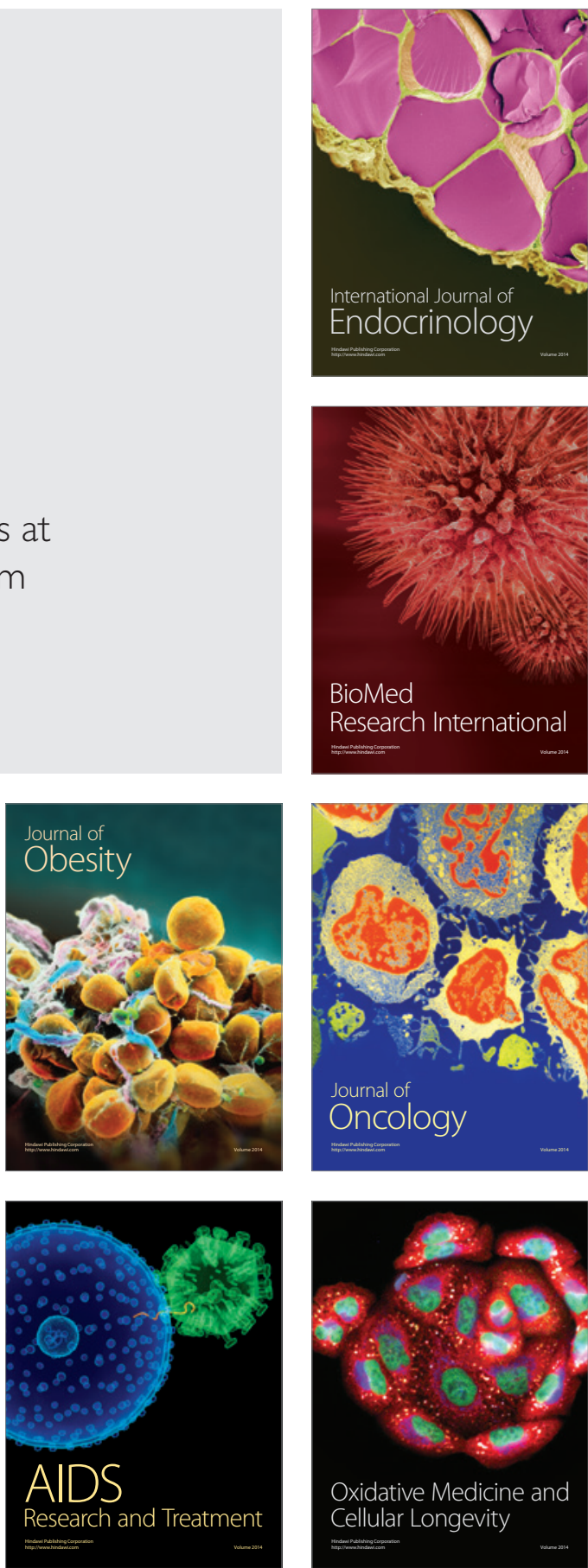